\title{
Influence of Hydrogen Dilution of Silane on the Properties of nc-Si:H films grown by Layer-by-Layer deposition technique
}

\author{
Goh Boon Tong ${ }^{1}$, Siti Meriam Ab. Gani ${ }^{2}$ and Saadah Abdul Rahman ${ }^{3}$ \\ Solid State Research Laboratory, Department of Physics, University of Malaya, \\ 50603 Kuala Lumpur, MALAYSIA \\ 1'gohbt@um.edu.my, ${ }^{2}$ smag@um.edu.my, 33aadah@um.edu.my
}

Keywords: nc-Si:H; LBL; XRD; Raman scattering; FTIR; AFM; FESEM

\begin{abstract}
Hydrogenated nanocrystalline silicon (nc-Si:H) films produced by layer-by-layer (LBL) deposition technique were studied. The films were grown at different hydrogen to silane flow-rate ratio on crystal silicon (111) substrate. The properties of films were investigated by X-ray diffraction (XRD), micro-Raman scattering spectroscopy, Fourier transform infrared (FTIR) spectroscopy, optical transmission spectroscopy, atomic force microscopy (AFM) and field emission scanning electron microscopy (FESEM). These properties showed dependence on the hydrogen dilution of silane. Appearance of XRD peaks at diffraction angles of $28.4^{\circ}$ and $56.1^{\circ}$ which correspond to silicon orientation of (111) and (311) respectively, were observed in all films indicating evidence of crystallinity in the films. Raman scattering results indicated that crystallinity in the films was due to the presence of nanocrystallites embedded in an amorphous matrix. The energy gap of the films showed dependence on the hydrogen content in the films. Increase in nanocrystallite size resulted in increase in disorder at low hydrogen dilution films but films remain homogenous with increase in nanocrystallite size for the high hydrogen dilution films.
\end{abstract}

\section{Introduction}

Hydrogenated nanocrystalline silicon (nc-Si:H) thin films, with nanometer sized crystallites embedded within an amorphous matrix demonstrate superior properties for applications such as solar cells and thin film transistors (TFTs) [1]. Solar cells fabricated using nc-Si:H are more stable during light soaking while TFTs are more efficient due to enhancement of carrier mobility. The role of hydrogen is important to the properties of nc-Si:H and proposed growth model of nc-Si:H such as surface diffusion and hydrogen etching models lead to a clearer understanding of the role of hydrogen in nc-Si:H [2]. In this work, we report our investigations on the effects of hydrogen dilution of silane on the properties of $\mathrm{nc}-\mathrm{Si}: \mathrm{H}$ films prepared by layer-by-layer (LBL) deposition technique using X-ray diffraction (XRD), micro-Raman scattering spectroscopy, Fourier transform infrared (FTIR) spectroscopy, optical transmission spectroscopy, atomic force microscopy (AFM) and field emission scanning electron microscopy (FESEM).

\section{Methodology}

The nc-Si:H films were deposited on silicon (111) substrates using LBL technique in a conventional home-built radio-frequency plasma enhanced chemical vapor deposition ( $\mathrm{rf}$ PECVD) system. During the LBL deposition, the silane $\left(\mathrm{SiH}_{4}\right)$ flow-rate was fixed at $5 \mathrm{sccm}$ while the hydrogen $\left(\mathrm{H}_{2}\right)$ flow-rate was varied for each deposition process to obtained films with different $\mathrm{H}_{2}$ to $\mathrm{SiH}_{4}$ flowrate ratios. The LBL technique involved alternating the growth of nc-Si:H films from the discharge of $\mathrm{H}_{2}$ mixed with $\mathrm{SiH}_{4}$ for 5 minutes followed by $\mathrm{H}_{2}$ plasma treatment on the pre-grown layer for 3 minutes for a period of 64 minutes ( 8 cycles). The substrate temperature and pressure were maintained at $300{ }^{\circ} \mathrm{C}$ and 0.8 mbar respectively. The $13.56 \mathrm{MHz}$ rf power density was fixed at 1400 $\mathrm{mW} / \mathrm{cm}^{2}$ throughout the deposition process for all films. The optical transmission spectra of the films were measured using a UV-VIS-NIR spectrophotometer and from these data the optical 
energy gap, $\mathrm{E}_{\mathrm{G}}$ was estimated [3]. XRD and micro-Raman spectroscopy using $514.5 \mathrm{~nm}$ Argon laser line were employed to investigate the crystallinity of these films. The average crystallite size, $\mathrm{d}_{\mathrm{XRD}}$ of the crystallites in the films was estimated using Scherrer's formula [4]. The crystalline volume fraction, $X_{C}$ was determined from the integrated intensities of Raman peaks at 520,500 and $480 \mathrm{~cm}^{-}$ 1 which corresponds to crystalline components, grain boundaries and amorphous components respectively [5]. The hydrogen content, $\mathrm{C}_{\mathrm{H}}$ and the ratio of integrated intensities of the $\mathrm{Si}-\mathrm{H}_{2}$ to $\mathrm{Si}-\mathrm{H}$ absorption bands were determined from FTIR spectra [6]. Surface morphology of the film was studied using AFM and FESEM.

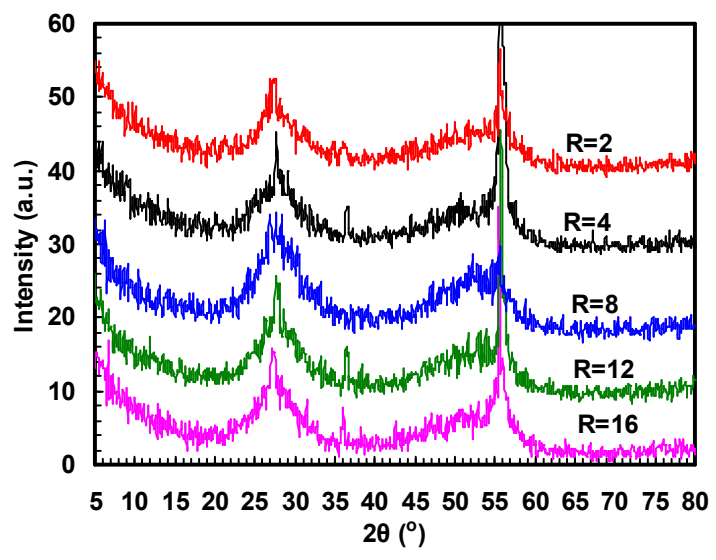

Fig. 1. XRD spectra of nc-Si:H films at different hydrogen to silane flow-rate ratio, $\mathrm{R}$.

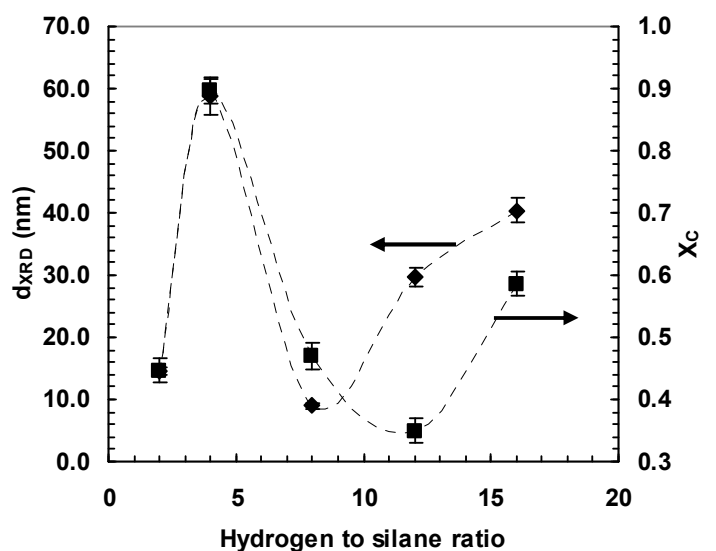

Fig. 2. Average crystallite size, $\mathrm{d}_{\mathrm{XRD}}$ and crystalline volume fraction, $\mathrm{X}_{\mathrm{C}}$ of nc-Si:H film versus hydrogen to silane flow-rate ratio, $\mathrm{R}$.

\section{Results and Discussion}

Appearance of sharp diffraction peaks corresponding to $\mathrm{Si}(111)$ snd $\mathrm{Si}(311)$ at $28^{\circ}$ and $56^{\circ}$ respectively (Fig. 1) shows the presence of crystalline phase in the structure of all films deposited at different hydrogen to silane flow-rate ratio, R. Fig. 2 illustrates the variation of average crystallite size, $d_{X R D}$ and crystalline volume fraction, $X_{C}$ with $R$. It is observed that $d_{X R D}$ increases to a maximum (60nm) with increase in $\mathrm{R}$ from 2 to 4 , then it decreases to a minimum $(10 \mathrm{~nm})$ when $\mathrm{R}$ increases to 8 followed by increase in $\mathrm{d}_{\mathrm{XRD}}$ with further increase in $\mathrm{R}$. The trend is the same for the variation of $\mathrm{X}_{\mathrm{C}}$ with $\mathrm{R}$ except that $\mathrm{X}_{\mathrm{C}}$ decreases to a minimum at $\mathrm{R}$ equals to 12 . High $\mathrm{X}_{\mathrm{C}}$ films contain higher crystalline component by fraction compared to the amorphous component. The films formed with $\mathrm{R}$ equals to 2 and 8 have small nanocrystallites embedded sparsely within the amorphous matrix of the film. Film with high $\mathrm{X}_{\mathrm{C}}$ of 0.9 and with large nanocrystallites of $60 \mathrm{~nm}$ is formed with $\mathrm{R}$ equals to 4 . Film with $\mathrm{R}$ equals to 12 has low $\mathrm{X}_{\mathrm{C}}$ with $30 \mathrm{~nm}$ sized nanocrystallites embedded within a highly amorphous structure. The film prepared with $\mathrm{R}$ equals to 16 is truly a two-phase material with reasonably sized nanocrystallites of $40 \mathrm{~nm}$ with $\mathrm{X}_{\mathrm{C}}$ of 0.6 . The plots of Hydrogen content, $\mathrm{C}_{\mathrm{H}}$ and optical energy gap, $\mathrm{E}_{\mathrm{G}}$ versus $\mathrm{R}$ are shown in Fig. 3. $\mathrm{C}_{\mathrm{H}}$ decreases to a minimum when $\mathrm{R}$ equals to 4 and then increases up to a maximum saturation value of $10 \%$ when $\mathrm{R}$ is equal to 12 . $E_{G}$ shows similar dependence on $R$ as $C_{H}$ but $E_{G}$ continues to increase with increase in $\mathrm{R}$ beyond $\mathrm{R}$ equal to 12 . The plots indicate that $\mathrm{E}_{\mathrm{G}}$ has some dependence on $\mathrm{C}_{\mathrm{H}}$. Increase in $\mathrm{R}$ reduces $C_{H}$ and $E_{G}$ for films with low $R(R=2,4)$, while high $R(R=8,12 \& 16)$ films produces a reversed dependence. Fig. 4 shows the variation of the ratio of the integrated intensities of $\mathrm{SiH}_{2}$ to $\mathrm{SiH}$ absorption bands, $I_{\mathrm{SiH}_{2}} / I_{\mathrm{SiH}}$ with R. $I_{\mathrm{SiH}_{2}}$ and $I_{\mathrm{SiH}}$ is proportional to the concentration of $\mathrm{SiH}_{2}$ and $\mathrm{SiH}$ bonds in the film respectively. The plot of $\mathrm{d}_{\mathrm{XRD}}$ with $\mathrm{R}$ is inserted in Fig. 4 to show the relationship between these parameters. High $I_{\mathrm{SiH}_{2}} / I_{\mathrm{SiH}}$ roughly indicates increase in structural disorder in the film structure. Films prepared with low $\mathrm{R}$ become more disordered with increase in nanocrystallite size while for high $\mathrm{R}$ films crystallite size has very little effect on the homogeneity of the film structure. Large $\mathrm{R}$ films and films with small nanocrystallites are more ordered 
comparatively. The AFM and SEM images of films prepared at R values of 4 and 16 confirm the results above as shown in Fig. 5. The film prepared with $\mathrm{R}$ equals to 4 has clusters of nanocrystallites of varied sizes (large and small) and are unevenly distributed. This explains the less ordered structure of the film. The images of the film with $\mathrm{R}$ equal to 16 shows a homogeneous film structure with evenly distributed nanocrystallites.

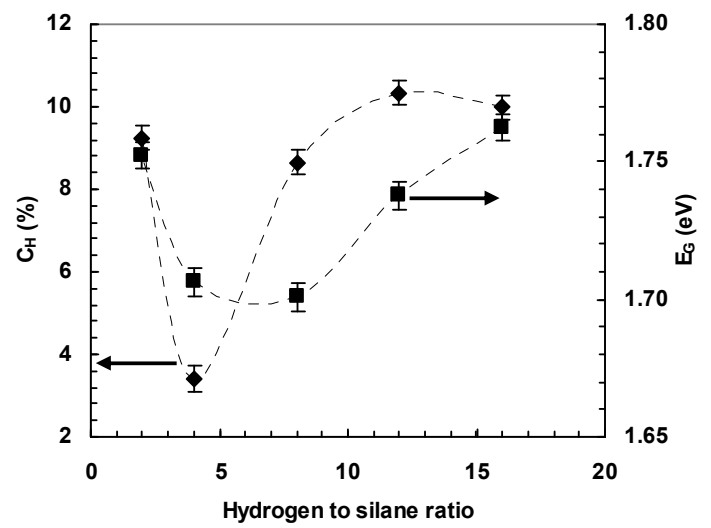

Fig. 3. $\mathrm{C}_{\mathrm{H}}$ and $\mathrm{E}_{\mathrm{G}}$ of nc-Si:H films versus hydrogen to silane flow-rate ratio, $\mathrm{R}$.
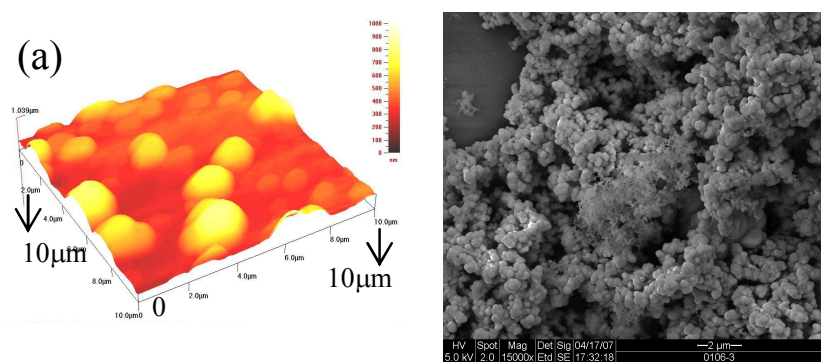

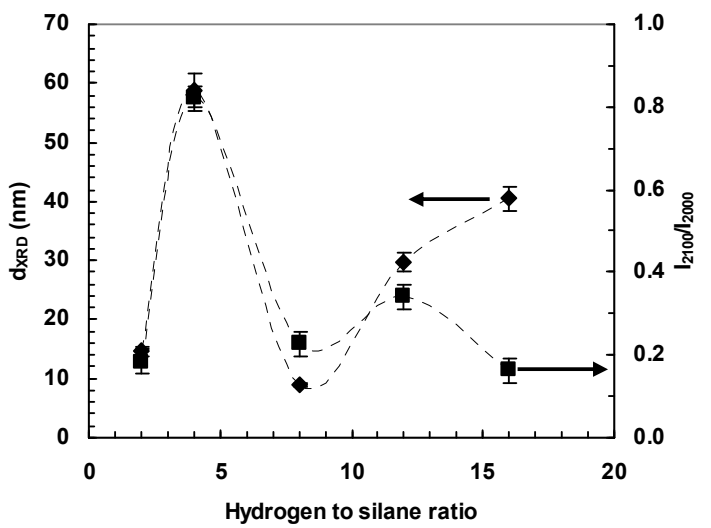

Fig. 4. Variation of $d_{X R D}$ and $I_{2100} / I_{2000}$ ratio with hydrogen to silane flow-rate ratio, $\mathrm{R}$.
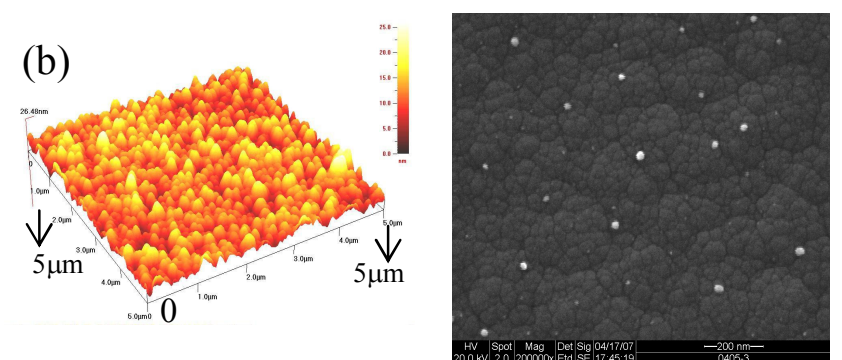

Fig. 5. AFM and field emission SEM images of nc-Si:H films at hydrogen to silane flow-rate ratio, R of 4 (a) and 16 (b).

\section{Conclusions}

Hydrogen to silane flow-rate ratio has significant influence on the $\mathrm{H}$ content and crystallite size in the nc-Si:H film produced using the LBL technique which directly influences the energy gap, crystalline volume fraction and the homogeneity of the film. The $\mathrm{H}$ plasma treatment on the pregrown surface of the nc-Si:H layer grown by LBL technique increases crystallite size and homogeneity in low and high hydrogen to silane flow-rate ratio films respectively.

\section{References}

[1] S.F. Chen, Y.K. Fang, T.H. Lee, C.Y. Lin, S.H. Chang and T.H. Chou: Thin Solid Films Vol. 515 (2007), p. 3844.

[2] Akihisa Matsuda: J. Non-Cryst. Solids Vol. 338-340 (2004), p. 1.

[3] J. Tauc: Amorphous and Liquid Semiconductors (Plenum Press, New York 1974).

[4] H.P. Klung and L.E. Alexander: X-ray Diffraction Procedures (Wiley, New York 1974).

[5] Keda Wang, Anthony Canning, J. R. Weinberg-Wolf, E. C. T. Harley and Daxing Han: Materials Research Society Vol. 808 (2004), p. A9.53.1.

[6] A.A. Langford, M.L. Fleet, B.P. Nelson, W.A. Lanford and N. Maley: Phys. Rev. B Vol. 45 (1992), p. 13367. 